\title{
ECOS DEL SENTIMIENTO ANTIMUSULMÁN EN EL SPILL DE JAUME ROIG
}

\author{
Francesca ESPAÑOL BERTRÁN \\ Universitat de Barcelona
}

Jaume Roig incluye en su Spill ${ }^{1}$ un episodio acaecido en Zaragoza, del que afirma haber sido testigo, que, junto con uno precedente, es testimonio de la multiplicidad de fuentes a que recurrió el autor valenciano al elaborar su obra. En este caso se trató de una colección de milagros ${ }^{2}$, pues ambos acontecimientos se divulgaron de forma

${ }^{1}$ R. Chabás, Spill o Libre de les dones per mestre Jacme Roig, Barcelona, 1905. Nosotros utilizamos una edición posterior: Jaume Roig: Llibre de les Dones o Spill, Ed. Francesc Almela i Vives ("Els Nostres Clàssics", col·lecció A, vol. 21), Barcelona 1928 <desde ahora Spill>. Para otras ediciones del mismo texto y una valoración general del texto y autor: M. de Riquer, A. Comas, Historia de la Literatura Catalana, vol. 3, Barcelona, 1980 (2na. ed.), pp. 213-244. Sobre el Spill ha defendido recientemente una tesis doctoral Antonia Carré en la Universidad de Barcelona.

${ }^{2}$ Existen otros episodios en el texto que apuntan en la misma dirección. Es lo que sucede con el que tiene como protagonista a un Crucificado. Se anima y mueve la cabeza milagrosamente, para saludar a un joven que la noche anterior ha evitado pecar con una monja en la iglesia (Spill, p. 96). Sin duda los parentescos con la historia del Cristo que da un manotazo a una monja que pretendía huir con su enamorado recogida en las Cantigas, existen. (Alfonso X, Cantigas de Santa Maria, Ed. J. Filgueira Valverde, Madrid, 1985, cantiga 59, pp. 108-110 [se señalan otros paralelos]). En líneas generales, sobre las fuentes a las que recurrió Roig en su Spill: R. Miquel i Planas, Spill o Libre de consells de Jaume Roig, Barcelona, 1929-1936. También: A. Carré, "Lletra de Batalla per l'Espill de Jaume Roig", Antipodas, V -en prensa-. En lo que atañe a la homilética véase especialmente la p. 5. Agradezco a Antonia Carré su amabilidad al facilitarme este trabajo todavía inédito. 
conjunta por esa vía. Se trata por un lado del prodigio del peregrino condenado injustamente a la horca, que se salva porque le sostiene el apóstol San Jaime; ${ }^{3}$ por otro, de un milagro eucarístico ${ }^{4}$. Vamos a tratar de éste último en las páginas que siguen, no sin atender antes brevemente al primero, ya que las acotaciones cronológicas a que da lugar la versión que de él nos transmite Roig son muy significativas. El milagro del ahorcado es uno de los más divulgados dentro del género hagiográfico y en nuestra península va ligado estrechamente al culto de San Jaime ${ }^{5}$. Precisamente lo protagonizan tres peregrinos que se dirigen a Compostela, pero el suceso no siempre se localiza en el mismo lugar.

Entre las versiones más antiguas y las posteriores se establece una diferencia en este punto. Si unas sitúan el milagro en Toulouse, más adelante su marco es Santo Domingo de la Calzada. Parece que esta novedad data de los primeros años del siglo $\mathrm{XV}$, pues se habla ya de ello en la crónica del viaje de un francés a Santiago en 1417. Al tratar sobre la ciudad riojana menciona la existencia de una jaula en el interior de la catedral con el gallo y la gallina de los que habla el milagro ${ }^{6}$.

Como hemos señalado, esta historia se recogió en distintas colecciones de prodigios y lo confirma, en ámbito español, una de las más reputadas. Las Cantigas de Alfonso X el Sabio incorporan el hecho

${ }^{3}$ Spill, pp. 65-66.

${ }^{4}$ Ibidem, 68-72. Véase el Apéndice 2 de este trabajo. Antonia Carré me informó que tiene un estudio sobre este mismo episodio que va a aparecer en breve, aunque nuestros puntos de partida respectivos no son coincidentes.

${ }^{5} \mathrm{~B}$. de Gaiffier, "Un thème hagiographique: le pendu miraculeusement sauvé", Revue belge d'archéologie et d'histoire de l'art, XIII, 1943, pp. 123-148. También: R. Llorens i Jordana, "Sobre una llegenda popular medieval. Un penjat preservat de morir miraculosament. Un gall i gallina ressucitats miraculosament", Arxiu de tradicions populars, 1, 1928, pp. 100-210, 266-274. L. Vázquez de Parga, J. M. Lacarra, J. Uría Riu, "Un tema santiaguista extendido por la peregrinación" en: Las peregrinaciones a Santiago de Compostela, Madrid, 1948 (reprt. Pamplona, 1992), vol. I, pp. 575-586, vol. III, pp. 92-162.

${ }^{6}$ Se trata del viaje del señor de Caumont. Lo publica J. Vielliard, Le guide du Pélerin de Saint Jacques de Compostelle, Macon, 1938, pp. 132-140. Como prueba de la difusión de esta variante también puede invocarse la noticia proporcionada por Vasari respecto a la temática de las pinturas que Pisanello ejecutaba en la iglesia del Temple de Florencia (Cf. P. Caucci, Las peregrinaciones italianas a Santiago, Santiago de Compostela, 1971, p. 121). 
haciendo recaer el mérito de la salvación del ahorcado en la Virgen? En esta misma fuente hallamos recopilado el milagro eucarístico que, con variantes, Jaume Roig describe algo más tarde ${ }^{8}$. Indudablemente tal proximidad y la tradicional coincidencia de ambos no puede ser casual. Si en el caso del milagro jacobeo el escritor valenciano parece hacerse eco de lo que a todas luces es una particularidad nueva del asunto, en el caso del prodigio de la Hostia, también se constata en su versión una divergencia muy significativa: la presencia de un musulmán que viene a suplantar al judío coprotagonista habitual de una de las versiones de esta historia.

Para articular esta serie de episodios que va desgranando en el segundo libro del Spill, que titula De quan fon casat, Roig utiliza como pretexto la supuesta crónica del viaje realizado por él a Santiago de Compostela como peregrino (donde vetli, del tot compli ma romeria, escribe). Si habla de Santo Domingo de la Calzada en el camino de ida, en el de vuelta menciona Olite (donde es testigo de un funeral muy pintoresco) y Alagón. Llega finalmente a Zaragoza donde pasa unos días (en Saragossa buidt la bossa tant aturant). La estancia le sirve para "presenciar" varios sucesos de los que da cuenta. En el texto se aúnan sin fisura aparente ficción y realidad. Si los hechos que narra responden a una tradición previa, los apuntes topográficos que proporciona para ambientarlos son lo suficientemente precisos para sospechar que conocia la ciudad. Es el caso de su observación: Alli's conforten los estrangés, no en vergés car no hi ha ${ }^{9}$ o las referencias a la capella, que és molt bella, de sent Miquel, sin duda San Miguel de los Navarros ${ }^{10}$, al Pilar,

${ }^{7}$ Alfonso X, el Sabio. Cantigas de Santa María ed. de J. Filgueira Valverde, Madrid 1985. El milagro del ahorcado se recoge en la cantiga número 175, pp. 285-288.

${ }^{8}$ Ibidem, cantiga 104, pp. 179-181. Se trata de la Cantiga sobre la mujer que quería hacer hechizos amorosos con la Hostia consagrada. Véase más adelante la nota 15.

${ }^{9}$ Esta observación puede contrastarse con la que proporciona Münzer: la tierra de los alrededores es árida y estéril, menos en donde puede regarse (J. Münzer, Viaje por España y Portugal (1494-1495), Madrid, 1991, p. 289).

${ }^{10}$ Esta iglesia, de estilo mudéjar, está documentada como parroquia en 1260 , aunque la fábrica actual parece datar del siglo XIV. 
y aun las que tienen que ver con la catedral (el lloc pus noble de la ciudad) y cuya dedicación conoce (al Salvador). Incluso localiza el final

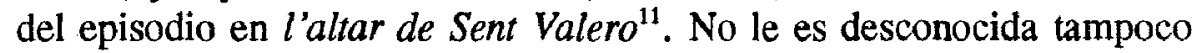
la existencia de la morería a donde acude la mujer de la historia en busca d'un sarrat, llur alfaqut, de quien Roig informa, más adelante, que el viernes al mediodía estaba ocupado en fer la sald ${ }^{12}$. El peso de lo real es sin duda un recurso del que se sirve Roig para hacer más verosímil lo ficticio, y el libro entero lo delata.

El milagro eucarístico del que se dice testigo tuvo por protagonista a una mujer desesperada por conseguir el amor de su marido que no tuvo inconveniente para lograr sus propósitos, en acudir a un musulmán, alfaqứ de la morería, en busca de consejo. Éste consintió en dárselo, pero puso como condición que el pago seŕa una Hostia consagrada. La mujer la obtuvo después de confesarse y comulgar en la iglesia de San Miguel. Tras colocarla en un pequeño cofre, volvió junto al árabe. El prodigio se produjo al abrir la caja y aparecer en su interior un bell infant tot rutilant e lluminos, molt gracids tot nu jaent. Al verlo, el alfaquí a quien Roig denomina perro malvat, ordena a la mujer que se vaya y que queme el cofre. Ella lo hace, pero Lo sant cosset de l'infantet roman il-les, del foc sospes. A pesar de que añade sarmientos y leña seca al fuego, el Niño sigue sin quemarse (sancer, no gens fumat ni alterat; brasses e foc, tot li fa lloc). Desesperada y sin saber qué hacer, acude a la mezquita donde sabe encontrará al alfaquí (era divendres entorn migdia. Ella sabia lo perro ca fer la sald en semblant hora $)^{13}$. Al tener conocimiento de lo que ocurre, éste teme

11 Aunque en la catedral existe actualmente una capilla dedicada a San Valero (data de mediados del XVD), sospecho que esta referencia de Roig alude a la capilla mayor que está presidida por un gran retablo en cuyo centro se emplazan tres relieves dedicados respectivamente a la Epifanía, a la Transfiguración y a la Ascensión. La predela, en cambio, está consagrada a los tres santos aragoneses por excelencia: Lorenzo, Valero y Vicente. Precisamente a este altar se destinaron los dos magníficos bustos-relicario de Valero y Vicente ejecutados por orfebres aviñoneses y que donó Benedicto XIII.

${ }^{12}$ El texto completo es como sigue: Era divendres entorn migdia. Ella sabia lo perro ca fer la salà (Spill, p. 70).

${ }^{13}$ Lo vell moret ix de l'alquible (Spill, p. 70), indicio, como la indicación recogida en la nota anterior, del conocimiento por parte de Roig de los hábitos 
por la vida de ambos: morts som ambdós si nostre cas pels populds serd sentit $^{14}$, le dice. Tras discurrir inmediatamente una posible solución que pasa por informar de lo ocurrido a un confesor de la catedral, el musulmán afirma: Llei mudaré, renegaré de Mafomet. Aixi hu promet. Los acontecimientos posteriores se desarrollan, según era de esperar, favorablemente. El obispo ordena al vicario y a su notario corroborar los hechos y, una vez confirmados, manda a un grupo de sacerdotes y gentes devotas a velar durante la noche al Niño. Al día siguiente, sábado, tras ser convocados todos los estamentos ciudadanos en la catedral y escuchada la prédica en la que se informa del prodigio, se organiza una procesión solemne que se dirige a la casa de la mala mujer para recoger el Cuerpo. Éste, descubierto y sobre un plato de oro, es trasladado a la catedral y depositado sobre el altar de San Valero donde lo velan de nuevo durante toda la noche. Convocadas las gentes para la celebración de la Eucaristía del día siguiente y llegado el momento de la consagración, el Niño adopta de nuevo la forma de la Hostia. En la narración nada se dice ya del alfaquí, pero se alude a la muerte de la mujer, tiempo después, a causa de un rayo (fert la dona'l llamp anant al camp), materialización, sin duda, del castigo divino.

El milagro que nos narra Jaume Roig corresponde, aunque con variantes, a uno de los que aparecen en distintos repertorios de prodigios: el de la mujer que quiere realizar un hechizo amoroso y se sirve para ello de la Hostia consagrada ${ }^{15}$. Respecto al desarrollo habitual de la historia, Roig introduce un elemento extraño: la figura del árabe como consejero. Sospechamos que se trata de una contaminación. Una de las historias de signo eucarístico que circularon por Europa

musulmanes, según ha puesto de relieve: M. J. Rubiera, Tirant contra l'Islam, Altea, 1993, p. 47 y ss.

${ }^{14}$ pres lo terrible por d'avalot (Spill, p. 70). Sobre la expresión avalot en este contexto, véase más adelante el apartado "Valencia y el sentimiento antimusulmán".

${ }^{15} \mathrm{Ya}$ hemos apuntado que se recoge en las Cantigas pero hay noticias del prodigio en recopilaciones anteriores. Es el caso de la de Cesáreo de Heisterbach que pudo conocerse en Castilla y servir como fuente en la elaboración de la colección de Alfonso X. Sobre ello véase: J. Ferreiro Alemparte, "Fuentes germánicas en las 'Cantigas de Santa María' de Alfonso X el Sabio", Grial, 31, 1971, pp. 31-62, especialmente pp. 45-46, 48-49. 
desde finales del siglo XIII era la correspondiente al milagro de Billettes, denominado así por situarse la acción en una calle parisina del mismo nombre el año $1290<$ Figs. 1 a $3>$. Una mujer había empeñado su mejor vestido a un judío y éste le puso como condición para devolvérselo la entrega de una Hostia consagrada. La mujer cumplió lo convenido y el usurero al tener el Sacramento del Altar en su poder lo profanó repetidamente hasta que su hijo advirtió a los transeúntes de lo que acaecía en el interior de la casa. Naturalmente la Hostia superó todas las pruebas a las que fue sometida (fuego, agua hirviendo, amartillamiento, etc.) y el milagro concluyó con el traslado solemne de la Sagrada Forma a una iglesia parisina donde se veneró por espacio de cuatrocientos años ${ }^{16}$. Estos hechos no sólo se divulgaron textualmente; la iconografía eucarística <Figs. 1 a $3>$ también contribuyó decisivamente a ello $y$, como veremos, son numerosos los testimonios que lo confirman. En la versión mixta que proporciona el escritor valenciano de ambas historias existe un detalle muy significativo y nuevo: uno de los dos coprotagonistas ha dejado de ser israelita para convertirse en musulmán. Indudablemente considerando la cronologia de la obra y el ambiente en la que se creó, éste no es un hecho incidental.

\section{El sacrilegio de las Hostias Consagradas: un eco antisemita.}

Por la Península circuló la creencia en la profanación de Hostias consagradas por parte de los judíos, como ocurrió en otras zonas de la Europa meridional ${ }^{17}$, pero ni ésta ni aquéllas parecen haber participado en la génesis de imputaciones de este género ${ }^{18}$. No fueron éstas las

${ }^{16}$ De miraculo hostiae a Judaeo Parisiis anno Domino MCCXC en: Recueil des Histoires des Gaules et de la France, XXII, p. 32. Sobre la incidencia del milagro en la iconografía gótica, ver la nota 27.

${ }^{17}$ Sobre este particular: P. Browe, "Die Hostienschändungen der Juden im Mittelalter", Römische Quartalschrift für christliche Altertumskunde und Kunstgeschichte, 34, 1926, pp. 167-197.

${ }^{18}$ Los historiadores que han rastreado estos temas antijudaicos coinciden en afirmar que su circulación por la península e incluso por la Europa meridional, es resultado directo de la influencia de los países del norte de Europa. Se comprueba este extremo en el caso concreto de la creencia en la muerte ritual. En 
únicas acciones reprobables que se les atribuyeron. También se les acusó de muertes rituales ${ }^{19}$ y del sacrilegio de imágenes, como la del Santo Cristo de Toledo ${ }^{20}$. El sentimiento racista que late en todo ello nació en el norte de Europa y se expandió hacia el sur utilizando como

Italia las primeras acusaciones se documentan tras alguna predicación que ha divulgado esas ideas entre el pueblo. Véase al respecto: G. I. Langmuir, "L'Absence d'accusation de meurtre rituel à l'ouest du Rhône" en: Juifs et judaisme de Languedoc, (Cahiers de Fanjeaux, 12), Toulouse, 1977, pp. 235-249.

${ }^{19}$ Véase el trabajo citado en la nota anterior $y$, para España, donde se documentan dos de estas muertes (Santo Dominguito del Val en Zaragoza el año 1250, o el Santo Niño de la Guardia en Ávila en 1491): M. Despina, "Las acusaciones de crimen ritual en España", El Olivo, 9, 1979, pp. 48-70,

${ }^{20}$ Sobre este punto puede ser revelador el camino realizado por una de las historias que tuvo mayor repercusión en la Europa de los siglos XIII y XIV: la profanación de un Crucifijo por parte de los judíos. G. I. Langmuir, "Historiographic Crucifixion", en Les Juifs au regard de l'histoire. Mélanges en l'honneur de Bernhard Blumenkranz, París, 1985, pp. 109-127. La historia se recoge tanto en Berceo (Gonzalo de Berceo, Milagros de Nuestra Señora, Ed. de B. Dutton, London, 1980, milagro XVIII, pp. 139-143), como en las Cantigas de Santa María (Alfonso X, Cantigas..., Cantiga número 12, pp. 31-32), en Gil de Zamora, etc., $y$ en todos ellos la acción se localiza en Toledo. Como se ha señalado, resulta paradójico que la narración de los hechos finalizara con alusiones a crudas matanzas de judios, como castigo a su conducta, cuando en la época en que se escribieron los versos de estas obras que situaban la acción de este milagro en Toledo, no existía aún ni en esta ciudad ni en Castilla un clima de relaciones judeo-cristianas tan deteriorado que posibilitara ataques cristianos de esta índole (Cf. J. M. Monsalvo Antón, "Mentalidad antijudía en la Castilla medieval", en: Xudeus e Conversos na Historia. 1: Mentalidades e Cultura, (Ribadavia 14-17 octubre 1991), Ourense, 1994, p. 84, nota 146). El milagro, claro está, no es de origen español. Vicente de Beauvais, que lo incluye en su Speculum Historiale, lo sitúa ya en Toledo, pero puede rastrearse su transmisión a través de otros autores y comprobarse que varía la localización del episodio de unos a otros. Las que pueden considerarse variantes del mismo tema se sitúan en algunos casos en Constantinopla, en otros en Beirut. Lo vemos en la Leyenda Dorada en el capítulo dedicado a la exaltación de la Cruz. También la recopilación debida al dominico Arnolfo de Lieja (1308-1310) ("El judío en los exempla medievales. El caso del Alphabetum Narrationum", en: J. Le Goff, Lo maravilloso y lo cotidiano en el Occidente medieval, 1985, p. 119). Para otras compilaciones hispánicas que lo incluyen: Cf. J. M. Monsalvo Antón, Mentalidad..., p. 73, nota 82 . 
vehículo las colecciones de milagros y ejemplos ${ }^{21}$ que sirvieron de fundamento a la prédica contemporánea y punto de partida de las colecciones de prodigios marianos vernáçulos como las de Berceo o Alfonso $X$ el Sabio. Cuando en algún caso se ha podido rastrear el desarrollo de los hechos, se confirma que ciertos actos sacrlegos se documentan por primera vez en determinados lugares tras una predicación que los ha descrito y, por tanto, divulgado.

De entre todos los actos reprobables protagonizados según la tradición por los judíos, los referidos a la Hostia consagrada fueron los que tuvieron mayor impacto. Por la propia naturaleza de la eucaristía, (la transubstanciación de la Sagrada Forma en el cuerpo y la sangre de Cristo) esta profanación revestía singular gravedad. Sin embargo, al sacrilegio siempre le sucede el prodigio y no debemos olvidar lo necesario que es lo segundo en el nacimiento y expansión de un determinado culto. El del Corpus Christi se benefició directamente de todas estas historias y, en relación directamente proporcional, aquéllos que la tradición había convertido en los instrumentos del milagro fueron perseguidos y odiados. Aunque existen noticias documentales sobre sucesos de esta naturaleza acaecidos en la propia península durante el siglo $\mathrm{XIV}^{22}$, la revisión de los procesos a que dieron lugar confirma

${ }^{21}$ Ha estudiado el papel difusor de estos repertorios: J. M. Monsalvo Antón, Mentalidad ..., p. 40 y ss. Aunque en ciertos casos se ha subrayado el carácter antijudaico de Berceo y de las Cantigas de Alfonso X (véase A. I. Bagby, "The Jew in the "Cantigas' of Alfonso X el Sabio", Speculum, XLVI, 1971, pp. 670-688, del mismo autor: "Alfonso X, el Sabio compara moros y judíos", Romanische Forschungen, LXXXII, 1970, pp. 578-583) otros trabajos posteriores han venido a matizar ciertos extremos (V. Hatton, A. Mackay, "Anti-semitism in the Cantigas de Santa Maria", Bulletin of Hispanic Studies, LXI, 1983, pp. 189 199). Últimamente: X. Filgueira Valverde: "Os xudeus nas Cantigas de Santa María", en Xudeus e Conversos na Historia, I. Mentalidades..., pp. 245-263. Evidentemente es muy distinto hacerse eco de un material hagiográfico foráneo que crearlo ex-profeso.

${ }^{22}$ Se trata de los hechos de Barcelona (1367), Perpinán (1367), Huesca (1377), Castelló de Farfanya (1383). Sobre el primero (4 de junio de 1367) la Crónica del Racional de la Ciutat, informa en estos términos: Execució de tres jueus $i$ un cristià acusats de profanar sagrades formes. Die veneris, quarta die juni, anno a nativitate Domini $M^{o} . C C C^{\circ}$ sexagesimo septimo, dominus infans Johannes dux Gerunde ac domini regis Petri primogenitus, eiusque generalis 
la mayor parte de las veces lo infundado de las acusaciones. Ello no obstante, los mismos hechos (fueran o no ciertos) demuestran hasta qué punto el pueblo se había sensibilizado ante las historias milagrosas propagadas por los predicadores y por los ciclos iconográficos que decoraban capillas, retablos y frontales consagrados al Corpus Chris$\mathfrak{t i}^{23}$. Al igual que en el caso de la muerte ritual, una encuesta en este

procurator, fecit cramarii et rosegar tres judeos, quorum unus vocabatur Proançal de Piere, alius Austruch Bione, et alius Mosse Gaylart; et fecit rosagar et ascortarar unum christianum qui fuit captus in villa Montisalbi eo qui fuerant inculpati quod dictus christianus vendiderat dictis judeis ab eo ementibus ostias sacratas (en: Recull de Documents $i$ Estudis I, fascículo II, Barcelona, 1922, pp. 140-141). En lo que respecta a Castelló de Farfanya (1382) se tienen noticias a partir de una carta del Infante Juan enviada al conde de Urgell: Lo primogenit: Comte car cosi. entes havem que de manament nostre es pres en Balaguer Bernat, de Vilanova de Balaguer, delat e inculpat que ella ab daltres, be ha V. anys, entraren ladronivolament en una esgleya de Castello de forfanya de daqui tragueren calzes dargent e custodies ad quatorze formes ho hosties sagrades. $E$ quen havets feta fer inquisició contra lo dit Bernat, lo qual ha confessat que ell fo a fer lo furt damunt dit, $e$ que aquelles XIIII formes son stades venudes a Juheus e han inculpats molts. E nos volriem saber la veritat daquest fet, qui es fort leig a tot cristia; Per co us pregam que, al pus tost que puxats, nos trametats complidament translat clos e segellat de la confessio del dit Bernat sobre aço feta e coses emergents de aquella; $E$ fer nos nets fort gran plaer. Data en Tarragona, sots nostre segell secret, a XXVIII de febrer M.CCCLXXXII. Primogenitii. A nostre car cosi lo comte Durgell (Documento publicado por J. M. Roca, "Notes d'Arxiu", Catalana, 15 d'octubre 1924, p. 318). En lo que respecta a lo sucedido en Huesca remitimos al trabajo de J. Miret i Sans, "El procés de les hòsties contre els jueus d'Osca en 1377", Anuari de l'Institut d'Estudis Catalans, IV, 1911-1912, pp. 59-80. Proporciona información general sobre todo ello: V. Baer Fritz, Historia de los judíos en la España Cristiana, vol. I, Madrid, 1981, pp. 334-335, 371-377.

${ }^{23}$ Significativamente las escenas que decoran la capilla de los Corporales en la catedral de Orvieto son comunes a gran número de frontales y retablos italianos (predela de Paolo Uccello), españoles (retablo de Villahermosa del Río, en Castellón, de Sijena, ahora en el Museo de Arte de Cataluña, el fragmentario de piedra de San Mateo, además de las tres tablas referenciadas en la nota 25). Todas estas obras trecentistas son buena prueba de la efectividad con que se canalizó la componente portentosa del nuevo culto. Sobre la iconografía eucarística: M. Vloberg, L'Eucharistie dans l'art, 2 vols. Grenoble-Paris, 1946, M. Rubin, Corpus Christi. The Eucharist in Late Medieval Culture, Cambridge, 1991. Para lo español M. Trens, La eucaristía en el arte español, Barcelona, 1952. También mi trabajo citado en la nota 25. 
sentido revela que el conocimiento de esta materia prodigiosa, en ocasiones por vía iconográfica, antecedió a las primeras acusaciones sobre profanación de Hostias consagradas en la Corona de Aragón ${ }^{24}$.

Una serie de testimonios avalan la divulgación de esas imágenes infames de las que se hacía protagonistas a los judíos. Es cierto que los herejes y los malos cristianos protagonizaron también algunos de estos episodios sobrenaturales ${ }^{25}$, pero el ensañamiento con el Sacramento del Altar fue patrimonio exclusivo de los israelitas. Hubo incluso ciertos hechos tomados como "reales" que contribuyeron a ello. Es el caso del milagro denominado de los "Billettes" al que ya nos hemos referido. Recordemos que sucedió en París y en un perfodo (1290) en el que los judios franceses fueron objeto de persecución cuyos ecos llegaron incluso a hacerse sentir en el Reino de Mallorca ${ }^{26}$. El milagro tuvo tal impacto que prácticamente todos los ciclos de imágenes consagrados al Corpus del Trescientos lo incorporan. Pueden aducirse ejemplos desde Italia a España pasando, naturalmente, por Francia ${ }^{27}$. Este milagro no

${ }^{24} \mathrm{Si}$ se contrastan las fechas que proporcionan los documentos (véase la nota 22) con los ciclos iconográficos conocidos ello es evidente. Tanto las dos tablas que presidían el altar del Corpus Christi en el monasterio de Vallbona de les Monges, ahora en el Museo de Arte de Cataluña, como el frontal de Queralps, son anteriores a 1367. Sobre su iconografía: F. Español Bertrán, Guillem Seguer de Montblanc. Un mestre trescentista escultor, pintor $i$ arquitecte, Montblanc 1994, pp. 101-114.

${ }^{25}$ Ibidem.

${ }^{26}$ Se decretó su expulsión de Francia en 1306. En 1315 les fue confiscada por parte del concejo municipal la nueva sinagoga que los judíos habían edificado en Palma de Mallorca. Apelaron al rey Sancho (1311-1321), pero éste se negó a ayudarlos. Se ha interpretado esta reacción real como un deseo de no molestar al monarca francés (Cf. J. L. Schneidman, L'Imperi catalano-aragonés (1200-1350), vol. II, Barcelona 1975, pp. 176-177, nota 44).

${ }^{27}$ Véanse las notas 24 y 25 . Se incluye en la predela de Paolo Uccello de la Galería Nacional de Urbino y, en la Corona de Aragón, en las tablas de Vallbona de les Monges y de Queralps, así como en los retablos de Sijena y Villahermosa del Río. Prueba de la difusión del tema en Francia lo es la afirmación de Alonso de Espina (s. XV) en su Fortalitium Fidei. Se dice ahí que las profanaciones realizadas por los judios son conocidas por las reproducciones que de estos hechos existen en las iglesias: ut omnes Gallie bene notum apud quos nota e manifiesta sunt. Nam in picturis et tabulis ecclesiarum multarum ascrivi hec sunt. Además, 
deja de tener relación con el que se recoge en las Cantigas (número 104) que, a su vez, obedece a una tradición previa ${ }^{28}$. En todos los casos se produce el milagro tras el robo de la Hostia por parte de una mujer que, o actúa por propia iniciativa, o ha sido incitada a ello por un judro. Es obvio que la versión que proporciona Roig del prodigio tiene mucho en común con esta materia previa, de la que él ofrece una síntesis a partir de las que pueden considerarse sus dos variantes principales. Si bien esta constatación encierra mucho interés desde el plano de la literatura hagiográfica, no es nuestro proposito detenernos en él. Nos interesa principalmente la transformación del coprotagonista. No sólo deja de ser judío para convertirse en un moro, sino que nuestro autor le aplica el calificativo infamante propio de éstos: perro malvat..., perro ca... ${ }^{29}$.

En el ideario que subyace tras estos episodios recogidos en las colecciones de milagros y exempla que llegan a nuestra península desde el norte de Europa ${ }^{30}$, que van a integrarse en las compilaciones de Berceo o de Alfonso X el Sabio, entre otros, el antijudaísmo es un hecho. Como minoría, fueron objeto de persecuciones tempranas en Alemania por razones diversas y esta producción literaria de la que tratamos se manifiesta impregnada de esa sensibilidad. Al importarse

Espina aduce como argumento de autoridad el testimonio de quien se lo contó: $e$ a vero que legi et in tabulis vidi fideliter enarrabo (tomado de J. M. Monsalvo Antón, Mentalidad ..., p. 81, nota 130). No deja de ser significativo que el castellano Alonso de Espina no haya conocido estas historias hasta entonces. Puede indicarnos que esta específica iconografía no se divulgó más allá de los reinos orientales y el dato podría relacionarse con otro hecho: por el momento no se han registrado aún casos reales o denuncias de profanaciones de Hostias en esa zona. Ello no va a ocurrir hasta finales del siglo XV (Ibidem p. 48).

28 Véanse las notas 8 y 15 .

${ }^{29}$ Sobre este apelativo que afecta también a lo iconográfico: J. Marrow, " 'Circumdederunt me canes multi': Christ's Tormentors in Northern European Art of the Middle Ages and Early Renaissance", Art Bulletin, LIX, 1977, pp. 167-181. Aunque el insulto parece haber sido aplicado tradicionalmente a los judíos, no podemos dejar de reseñar la alusión: perro Mahoma, que se halla en la Cantiga 192. En ella también se califica al moro protagonista de falso, característica nuevamente más propia del pueblo judio que del musulmán.

${ }^{30}$ G. Dahan, "Les juifs dans les Miracles de Gautier de Coincy", Archives Juives, 16, 1980, pp. 41-49, 59-68. 
estos exempla, se ayudó a difundir el racismo subyacente en ellos, a pesar de que tal sentimiento era, en principio, extraño al ámbito peninsular. Incluso se ha hecho hincapié en lo anacrónico de un milagro que divulga, entre otros, Berceo, y que se localiza en Toledo. Se trata de la profanación de un Santo Cristo, y concluye con la referencia a unas matanzas de judíos. Lo curioso es que la cronología de los hechos corresponde a un período en el que ni en Castilla ni por supuesto en Toledo, se vivía un clima favorable a esas persecuciones, ya que la convivencia judeo-cristiana era buena ${ }^{31}$. Si en las obras de Berceo o Alfonso $\mathrm{X}$ detectamos rasgos contrarios a los israelitas a través de estos episodios de elaboración foránea, las crónicas de los milagros vernáculos protagonizados por musulmanes no manifiestan un sentimiento equivalente. En este caso la pugna interracial se establece fundamentalmente en el plano militar. De ahí que los sacrilegios de imágenes se produzcan en el marco de los saqueos posteriores a la conquista, de razzias puntuales, etc ${ }^{32}$. Lo antijudío, sin embargo, fue asimilado en mayor o menor grado, y quizá dé la medida de su incidencia en la sociedad de la época, el contenido de dos t́tulos de la VII Partida. Mientras en uno de ellos, el XXV, "De los moros", no hallamos nada de carácter reprobable, en la ley II del XXIIII dedicado a la otra minoría, ocurre lo contrario. Tras el epígrafe: En qué manera deben facer su vida los judios mientras vivieren entre los cristianos, et cuales cosas non deben usar nin facer segunt nuestra ley, et qué pena merescen los que contra esto ficieren ${ }^{33}$, el redactado pasa a hacerse eco de la creencia en la muerte ritual de un Niño en manos de lo judíos el día de Viernes Santo, a quien, a imagen de Jesucristo, se infligían todos los tormentos de la Pasión. El texto es el siguiente:

Et porque oyemos decir que en algunos lugares los judios ficieron et facen el dia del Viernes Santo remembranza de la pasión de nuestro senor Jesucristo en manera de escarnio, furtando los ninos et poniendolos en la cruz, o faciendo imágines de cera et crucificandolas cuando los nifos non pueden haber, mandamos que

\footnotetext{
31 Véase la nota 21.

32 Véanse como ejemplo las Cantigas 99, 183, 215, 229 y 345.

33 Alfonso X, Las Siete Partidas, vol. III, Madrid, 1807.
} 
si fama fuere daqui adelante que en algun lugar de nuestro seftorio tal cosa sea fecha, ni se pudiere averiguar, que todos aquellos que se acertaren en aquel fecho que sean presos, et recabdados et duchos antel rey, et despues que él sopiere la verdad, debelos mandar aviltadamente cuantos quier que sean...

\section{Valencia y el sentimiento antimusulmán}

El 9 de julio de 1391 se produjo el asalto a la judería de Valencia. Los disturbios, según recoge la crónica de los hechos que se hizo llegar al rey, comenzaron por la mascarada que organizaron unos cincuenta niños a la puerta de la judería, a consecuencia de la cual uno de ellos perdio accidentalmente varios dedos de una mano. Tras ser cerrado el acceso al barrio, corrio el rumor de que los judíos mataban a los niños y a los cristianos que habían quedado dentro, y éste fue el detonante del saqueo. El lunes siguiente, cuando los jurados de Valencia se hallaban reunidos para evaluar los hechos, oyeron, segín ellos mismos señalan: que alcuns, en la partida del mercat, creem que cevats de la juheria començaven metre remor vers la moreria per esvair aquella.. ${ }^{34}$. Por entonces ya se habían registrado algunos asaltos a morerías valencianas, siendo especialmente graves los de Crevillente (1385), Xàtiva y Elda $(1386)^{35}$. En 1391 se abortó el de la ciudad de Valencia, pero se detecta un nuevo período de inseguridad entre 1397 y 1399 a raíz de la organización de una cruzada a Berbería. En 1396 unos corsarios de este origen atacaron Torreblanca en la costa castellonense y se llevaron la custodia de la iglesia con su contenido. La acción, que probablemente

${ }^{34}$ Para los dos documentos que recogen los hechos: A. Rubio Vela, Epistolari de la València medieval, València, 1985, pp. 269-275. Publica otro documento relativo a estos hechos: M. T. Ferrer Mallol, La frontera amb l'Islam en el segle XIV. Cristians i sarrains al País Valencià, Barcelona 1988, pp. 384-386. Se trata de una carta del infante Martín a su padre en la que informa que: $E$ aquell mateix dia, quaix ora de dinar molta gent se começà de avalotar contra los moros de la dita ciutat e de feyt anaren a la moraria. E tantost yo, sabent-ho, cavalquí. E trobé pers la dita moraria poble infinit de la dita ciutat e, per ço com I d'aquells, qui era castellà, començava a robar e havia ja robat en la juheria, fiu-lo penjar.

${ }^{35}$ Ibidem, pp. 24-29. 
no habŕa sido otra cosa que un episodio más del saqueo, se interpretó como un sacrilegio y su impacto fue de tal magnitud que se organizó una cruzada con el fin de recuperar las Sagradas Formas ${ }^{36}$. La documentación contemporánea informa de hasta qué punto la acción de unos piratas repercutio en la Corona de Aragón, y muy en particular en el Reino de Valencia, lugar desde el que zarpaba la flota. Se predicó para mover a la participación de las gentes en ella en muchos lugares $y$, naturalmente, dada su razon de ser, podemos prever el contenido de esos sermones inflamados. Debieron nutrirse de la materia eucarística que había circulado a lo largo del siglo XIV por los territorios de la Corona de Aragón, en la que, como se ha visto en las páginas precedentes, la minorfa israelita había protagonizado las acciones más reprobables y dado pie, en consecuencia, a los hechos más portentosos. Quizá incluso esa revitalización eucarística justifique la ejecución de sendos retablos consagrados al Corpus Christi en el área castellonense ${ }^{37}$. Que

${ }^{36}$ A. Ivars, Dos Creuades valenciano-mallorquines a les costes de Berberia (1397-1399). Estudi documenal, València 1921, M. T. Ferrer Mallol, op. cit. , p. 26 y ss. En la cruzada participó el poeta Andreu Febrer que escribió, además, dos poesías sobre el tema (M. de Riquer; A. Comas, Història..., vol. I, pp. 592595). Sobre esta cruzada y sus ecos en otros territorios de la Corona de Aragón puede ser significativa la noticia que sigue. Se registran voluntarios para participar en ella en lugares del Campo de Tarragona como la Selva del Camp. Un testamento dictado en 1398, poco antes de la partida, indica: ire ad sacrum passagium ac viagium Berberie contra Christi infideles ad deliberandum a captivitate corpus altissimi creatoris domini nostri Jesuchristi ... En la misma escribanía se contabilizan otros cuatro testamentos por el mismo motivo (publica estos datos: J. Pié Faidella, Annals inèdits de la Selva del Camp de Tarragona, Barcelona, 1899-1913 (reprt. Tarragona, 1984), pp. 202-203). Tarragona participó activamente en esta empresa a instancias del arzobispo fñigo de Vallterra que era de origen valenciano. Consta que el cabildo mandó fabricar un galeote (el San Antonio) y la ciudad otro más (E. Morera Llauradó, Tarragona Cristiana, vol. II-2, Tarragona, 1954 (reprt. Tarragona, 1982), pp. 704-705).

${ }^{37} \mathrm{Me}$ refiero a los de Villahermosa del Rio (pintura) y San Mateo (escultura). Para el primero no contamos con documentación directa, pero a partir del análisis estilístico se han barajado unas fechas de ejecución que oscilan entre 1375 y 1400. (S. Llonch, "Pintura gótica valenciana", Anales y Boletín de los Museos de Arte de Barcelona', XVIII, 1967-1968, pp. 63-67, 77-79). Un margen, por tanto, muy adecuado, respecto a la interpretación que proponemos. En lo que concierne al de San Mateo, tampoco disponemos de datos directos sobre él. Se 
alrededor de esta cruzada se tejí una urdimbre ideológica que debió favorecer a los ojos de los cristianos la asimilación del árabe al judío parecen apuntarlo algunos hechos. Debieron de escribirse textos propagandistas al respecto y el párrafo de uno de ellos, una composición que lleva por título la Croada, dice: Anem ab grans jornades / Totes faenes lexades, / Bona gent recobrar, / Les hosties sagrades / Que los cans nos han levades / No les volen dar ${ }^{38}$. Recordemos que el apelativo, "perro" cuenta con una larga tradición previa que lo vincula más a judíos que a musulmanes ${ }^{39}$. El uso que de él se hace en el verso anónimo es el mismo que emplea Jaume Roig unos años más tarde en el episodio que estamos analizando. Probablemente la cruzada a Berbería ayudo a la satanización del árabe merced al desplazamiento sobre esta minoría de una serie de prejuicios que habían sido hasta entonces patrimonio exclusivo de otra. En particular las profanaciones de imágenes y hostias sagradas. A lo largo de todo el siglo XIV, la inseguridad de la frontera con Granada había generado un sentimiento antimusulmán que, según hemos referido, en Valencia tomó forma en los ataques escalonados a ciertas morerías, pero a esa situación vino a añadírsele otro hecho. Tras el pogrom de 1391, se habran producido conversiones multitudinarias ${ }^{40}$. El odio "al otro", a "lo diferente", había perdido en parte su razón de ser en lo que se refiere al pueblo israelita. Quedaba, no obstante, la población mudéjar que participaba de ese mismo carácter marginal, aunque, al no ser deicida y discurrir sus fuentes de riqueza por unos cauces distintos a los de éstos, su situación

conserva fragmentariamente y puede fecharse avanzada la segunda mitad del XIV (F. Español, "Atribuible al Mestre de Sant Mateu. Imago Pietatis. Compartiment d'un bancal de retaule", en Fons del Museu Frederic Marès, I), Barcelona, s.a. (1990), pp. 415-416).

${ }^{38}$ J. Pié Faidella, op. cit., p. 203. Está copiada en un cuaderno (de origen tarraconense) que contiene también un texto dramático mariano. El manuscrito se halla en la actualidad en el Archivo Diocesano de Tarragona.

39 Véase la nota 29.

40 Sobre la ruina de las juderías del Reino de Valencia después de los pogroms y la conversión generalizada al cristianismo: J. Hinojosa, "Bosquejo histórico de los judíos en tierras alicantinas durante la Baja Edad Media" en: ler. Col.loqui d'historia dels jueus a la Corona d'Aragó. Actes (Lleida 1989), Lleida, 1991, pp. 207-220. 
respecto a la mayoría cristiana había sido, hasta entonces, sensiblemente distinta a la de éstos. La desaparición del judío como objeto de persecución coincide en Valencia con la cruzada a Berbería y a esto se suma el progresivo sentimiento antimudéjar gestado al socaire de las pugnas con el Reino de Granada a lo largo del Trescientos. En este contexto no debe extrañarnos la trasposición al árabe de ciertos comportamientos negativos, tales como la profanación de hostias o de imágenes. Si respecto a lo primero, aun siendo bien conocido que los autores de la profanación de Torreblanca habían sido berberiscos, hubo que advertir explícitamente a la población valenciana que el enemigo era el árabe del exterior ${ }^{41}$, fue porque la población no distinguía con nitidez los límites entre los mudéjares y los "otros", porque el conflicto había adquirido ya tintes raciales. Otro indicio sobre este estado de cosas lo proporciona la denuncia del sacrilegio de una imagen de San Juan Bautista que era titular de un retablo pintado en el castillo de Murla $^{42}$. Sucedió en 1420 . Se conoce la noticia porque desde Valencia se envió un experto al lugar para que informara sobre la veracidad de los hechos. Se decía que endret del ventre de una ymatge de Sent Joan Babtista, que era deboxada e pintada en 1 retaule antich que estaba en la esgleya, dins lo dit castell, era exida sanch per un clau que's dehia esser ficat endret lo dit ventre de la dita ymatge per moros infels, en gran menyspreu de la Santa Fe Catholica, pero se vio que todo era infundado porque: a sanch que's mostrave esser sobre la dita cabota del dit clau e entorn d'aquella no era sanch que per raho del dit clau fos exida de la dita imatge, segons se dehia, mas era sanch, segons l'escampament d'aquella, d'algun trof de fetge o de lleu de sanch presa d'alcuna res, que per alcuna persona fon lançat manualment vers lo dit retaule. La imputación a moros infels del hecho que relata el documento, no deja de parecernos maliciosa. Significativamente en Castilla también se llegó a una situación similar con respecto a los árabes a lo

${ }^{41}$ M. T. Ferrer Mallol, op. cit., p. 26 y ss. y especialmente el documento 182 (p. 417). También docs. 179, 181, 183, 184, 185, 186, 187, 188.

${ }^{42}$ Publica el documento: F. A. Roca Traver, El tono de la vida en la València medieval, Castellón de la Plana, 1983, doc. 25, p. 152. ref. p. 134. Dado su interés, lo incluimos como apéndice número 1 de nuestro estudio. 
largo del siglo XV y la acusación de sacrilegio de imágenes vuelve a ser uno de los argumentos en los que se fundamenta el odio ${ }^{43}$.

Si en 1391 pudo detenerse el asalto a la morerfa de la ciudad de Valencia (el populacho acudía a ella no en primer lugar, sino tras haber saqueado la judería, no se olvide), no sucederá lo mismo 64 años más tarde. El día 1 de junio, de 1455, fiesta de la Trinidad, acabo materializándose el asalto de la aljama ${ }^{44}$. La festividad en la que acaeció es extraordinariamente emblemática, y no debe olvidarse tampoco que días después (el 19 de junio) tenfa lugar la canonización de San Vicente Ferrer en Roma, debido a lo cual el estado de opinión que habrían propiciado los predicadores desde los púlpitos valencianos también debió de ayudar a precipitar los hechos.

Cuando Jaume Roig redactó su Spill este ataque a la morería era algo muy reciente. Aquéllos que han analizado la obra no han dejado de notar ciertas referencias puntuales del autor que iluminan sobre la cronología del texto. Hay una muy significativa para nosotros, aquélla que alude a Vicent Ferrer, lo sant darrer canonizat ${ }^{45}$ que nos hace concluir que cuando Roig elaboró esta parte del Spill no sólo había transcurrido muy poco tiempo desde la canonización del santo, sino del saqueo a la morerfa, hecho que, indudablemente, permite analizar desde una perspectiva muy concreta el milagro eucarístico que Roig sitúa en Zaragoza y ciertas observaciones que pone en boca de sus protagonistas, como el temor manifestado por el sarrat alfaqut al avalot si, según añade, lo nostre cas pels populas serd sentit. Indudablemente el episodio que narra y al que hemos dedicado las páginas precedentes, no fue real. Pero desde una perspectiva histórica resulta muy reveladora la incorporación del moro a un episodio relacionado con el sacrilegio de hostias consagradas, ultraje imputado tradicionalmente hasta entonces

${ }^{43}$ M. A. Ladero Quesada, Los mudéjares de Castilla y otros estudios de historia medieval andaluza, Granada 1989, p. 81, nota 146. En el Memorial de agravios de Cigales ( 5 diciembre de 1464) se denuncian agravios a las imágenes de las iglesias por parte de los mudéjares y, como consecuencia, la sentencia aplica restricciones similares a las que se sometió a los judíos con anterioridad.

${ }^{44}$ M. Ardit Lucas, "El asalto a la morería de Valencia en el año 1455", Ligarzas, 2, 1970, pp. 127-138.

${ }^{45}$ Cf. M. de Riquer; A. Comas, Història de la ..., III, p. 220. 
a los judíos. Jaume Roig pudo conocer desde textos hagiográficos ${ }^{46}$ hasta retablos que incorporaban secuencias de este género en los que inspirarse, pero la particularidad que subrayamos supone una notable voluntad de contemporaneizar las historias que narra. En la Valencia del entorno de 1455 (recordemos que la redacción de la obra se sitúa entre esa fecha y 1461) era absolutamente creíble la participación de un árabe en un hecho de esas características. A lo largo de los años se había desarrollado el proceso de criminalización del musulmán-mudéjar y el racismo se había materializado dramáticamente en el asalto a diversas morerías, a las que sucedio, finalmente, la de la capital del Reino. Roig con su episodio zaragozano no hizo otra cosa que reflejar ese sentimiento colectivo.

\section{APÉNDICE I}

1420, Murla

Original: A.R.V. Cartas de Maestro Racional, C. 40, fol. 308 Publicado: F. A. Roca Traver, El tono de la vida en la Valencia medieval, Castellón de la Plana, 1983, doc. 25, p. 152, ref. p. 134.

Com a audiencia mia fos pervengut que en lo castell del loch de Murla se fos esdevengut que endret del ventre de una ymatge de sent Johan Babtista, que ere deboxada e pintada en I retaule antich qu'estava en la esgleya, dins lo dit castell, era exida sanch per un clauque's dehia esser ficat endret lo dit ventre de la dita imatge per moros infels, en gran menyspreu de la Santa Fe Catholica, acordi de trametre n'Arnau Ferragut, barber e cirurgia de la cita ciutat de Valencia per veure e regonexer e examinar si la cosa era axi com se dehia e encerquar qui eren aquellsqui semblant cosa havien comesa $e$

46 Desde el punto de vista hagiográfico no debemos olvidar que en la catedral de Zaragoza, aunque Roig no diga nada al respecto, se conservaban las reliquias de San Dominguito de Val, el niño mártir de cuya muerte fueron acusados los judios en 1250. Naturalmente la existencia de un culto particular supone la difusión de leyendas relativas al mismo y es factible suponer que las que giraron alrededor de éste tuvieran, por razones obvias, un fuerte carácter antijudaico. Si Roig, como parece, conoció Zaragoza, otra vía de información puede haber sido ésta. 
assatiada, per tal que d'aquells fos feta la punició $e$ castich que's pertanya; lo qual dit n'Arnau Ferragut, de mon manament e ordinacio, ensemps ab I jove seu, ab ses cavalcadures anaren al dit loch, muntaren en lo dit castell et vist e regonegut lo dit feyt fon atrobat en veritat que lo dit clau era cabota de I clau qui era estat ficat en lo dit retaule, ladonchs con fon trobat per fermament d'una barra que estava detras lo dit retaule, de la qual cabota de clau, per la antiquetat del dit retaule se era levat lo guix e que la sanch qu'es mostrave esser sobre la dita cabota del dit clau e entorn d'aquella no era sanch que per raho del dit clau fos exida de la dita ymatge, segons se dehia, mas era sanch, segons l'escampament d'aquella, d'algun trof de fetge o de lleu de sanch presa d'alcuna res, que per alcuna persona fon lançat manualment vers lo dit retaule.

\section{APÉNDICE II}

J. Roig: Llibre de les dones o Spill, Ed. F. Almela i Vives, Barcelona 1928, Segon llibre ("De quan fon casat") Segona part ("Com volgué pendre beguina"), pp. 67-72.

Passi lo riu gros d'Aragó. En Alago desfiu ma trossa. En Saragossa galant entrl $e$ dret tirl descavalcar al sant Pilar, qual, quant vivia santa Maria angels obraren; ells lo portaren per salvetat a la ciutat on preicant l'apdstol sant més gent l'ot e's convertt. Puis a la Nau (hostal), pensau millor) post ... Ans qu'em partis, una torbada dona darbada, tan rabiosa com ansiosa de ser amada, entenebrada per lo diable feu cas mirable, gran erogdncia fet d'importancia e de gran spant, contaminant la sua fe. No sé per què; sols gelosia crec la hi movia. ella's clamava molt la tractava son marit mal. Pensd al Raval o Moreria consell hauria d'un sarrat, llur alfaqut. Per son diner, lo fetiller dix, si'l pagava e li portava ben amagat lo cors sagrat cert ell faria que la volria bé son marit. Prest fet e dit. En la capella, que és molt bella de sent Miquel, calat lo vel ella's confessa; ab mala fressa pres falsament lo sagrament sant de l'altar; com qui torcar-se vol la boca, la santa coca se'n trac sancera; en candelera o cofrenet, com pus secret pogué, tanca. De fet tornà, dix ja'l tenia on ho volia. Dis que hu portds. E com cuitds, ab molta raxa obrint la caxa que hi hac dexat, fon transformat un bell infant, tot rutilant e lluminds, molt gracids, tot nu jaent. Lo qual veent, com qui sol mira, al moro tira tota sglaiada, 
alienada, fora de si. Lo tagart, perro malvat, tot atronat, dix se'n tornàs, tot ho cremas, proveiria per altra via.

La renegada, endiablada, folla, dement, Déu no tement, no res dubtatnt ni gens pensant en lo que feia (crec que no hi veia) féu gran foguera; la candelera mes sus en mig; apres afig llenya i carbo; tost lo caxó fon ben cremat, tot abrasat. Lo sant cosset de l'infantet roman il-lès; del foc sospès lo seu cremar, resta la llar mirablement pus resplandent, e semblant viu entre'l caliu no socarrat. Tan lleig pecat no'l puc narrar sens fort plorar; lo paper mulle, lo ja scrit sulle lacrimejant. Continuant sos pensaments, porta sarments, llenya molt més, pi sec hi més, més foc encén, molt fort entén fer tot de cendres. Era divendres entorn migdia. Ella sabia lo perro ca fer $l$ sald en semblant hora. Arrapa's plora, no sap que fer; veia'l sancer, no gens fumat ni alterat; brasses e foc, tot li fa lloc. Cega per ira, lo cami gira ves la mesquita; plorant recita son mal novell, per mal consell seu quant ha fet. Lo vell moret ix de l'alquible, pres-lo terrible por d'avalot; pensa quan pot, en si discorre; sols li ocorre dir a la fembra: - Qui spines sembra, delcalc no vaja: qui molt s'ensaja a l'aigua anar, ell ha llexar lo coll a l'ansa. Tota speranca tinc ja perduda si non's ajuda Déu poderos; morts som amdós si nostre cas pels populds será sentit. Pregam partit tal que'ns delliure que pugam viure; abdos morrem, si no correm dret a la Seu e vós al peu del confessor, lo gran error que fet haveu confessareu, $e$ io mon mal al general major vicari sens gens mudar-hi recitaré acusaré mon falliment. Discretament proveiran si'ns guiaran e som estorts abdos de morts. Llei mudaré, renegaré de Mafomet. Aixi hu promet.-

Tot axi's féu. Bisbe sabé-hu. Mand'l vicari ab son notari se desfressassen e que hi anassen a la vesprada aprés tocada l'uracio. Relació certa li feren del que pogueren un tant mirar. Puis féu manar al gran prior son confessor, ab certs devots bons sacerdots, la nit vetlassen, tot ho guardassen dant bon recapte. Dema dissabte hac ajustats los quatre estats, homens de titols, los dos capttols, religions, nobles barons, e cavallés, los consellés e consolat de la ciutat gran part del poble; al lloc pus noble. Sent Salvador, ab gran fervor volgué preicar, manifestar lo dit atràs, tan horrén cas exorbitant, más confermant la nostra fe. Devot e bé féu lo sermo. Gran professo molt singular féu arreglar: primer les creus; ab altes veus, los coronats $e$ 
ordenats "Pange" cantant; los llecs portants llum en ses mans, e les campanes sens mans humanes pels campands. E com tornds ab gran honor, en un plat d'or lo cos posat, fon desposat, sense tancar, sobre l'altar de sent Valero. E tot lo clero llegint, vel-lant e contamplant tota la nit, lo Sant Sperit hac revelat al sant prelat la'ucaristia que la faria. De fet ordena res no s'hi vena dema diumenge e no s'hi menge carn per algú; tothom dejú vinga escoltar lo sant orar. Volgués vestir a missa dir del Sagrament solemnament. Adés cantant, adés plorant, per la oferta ell no concerta ni vi ni pa; sols en la mà lo sant cos pres. Dient lo ves, com l'ofert, se converti cobrant la forma segons la norma qu'en l'hostier per lo ferrer era esculpida; arredonida com fon primera hostia vera, la qual sumi.

Axt fint la furiosa e perillosa d'avalot gesta: solemne festa miraculosa e profitosa als bons e fels; als mals, infels e folls $e$ increduls, heretges èmuls contrariosa; e vergonyosa a dones tant. Per temps avant sabt la fi, com cert fert la dona'l llamp anant al camp. 


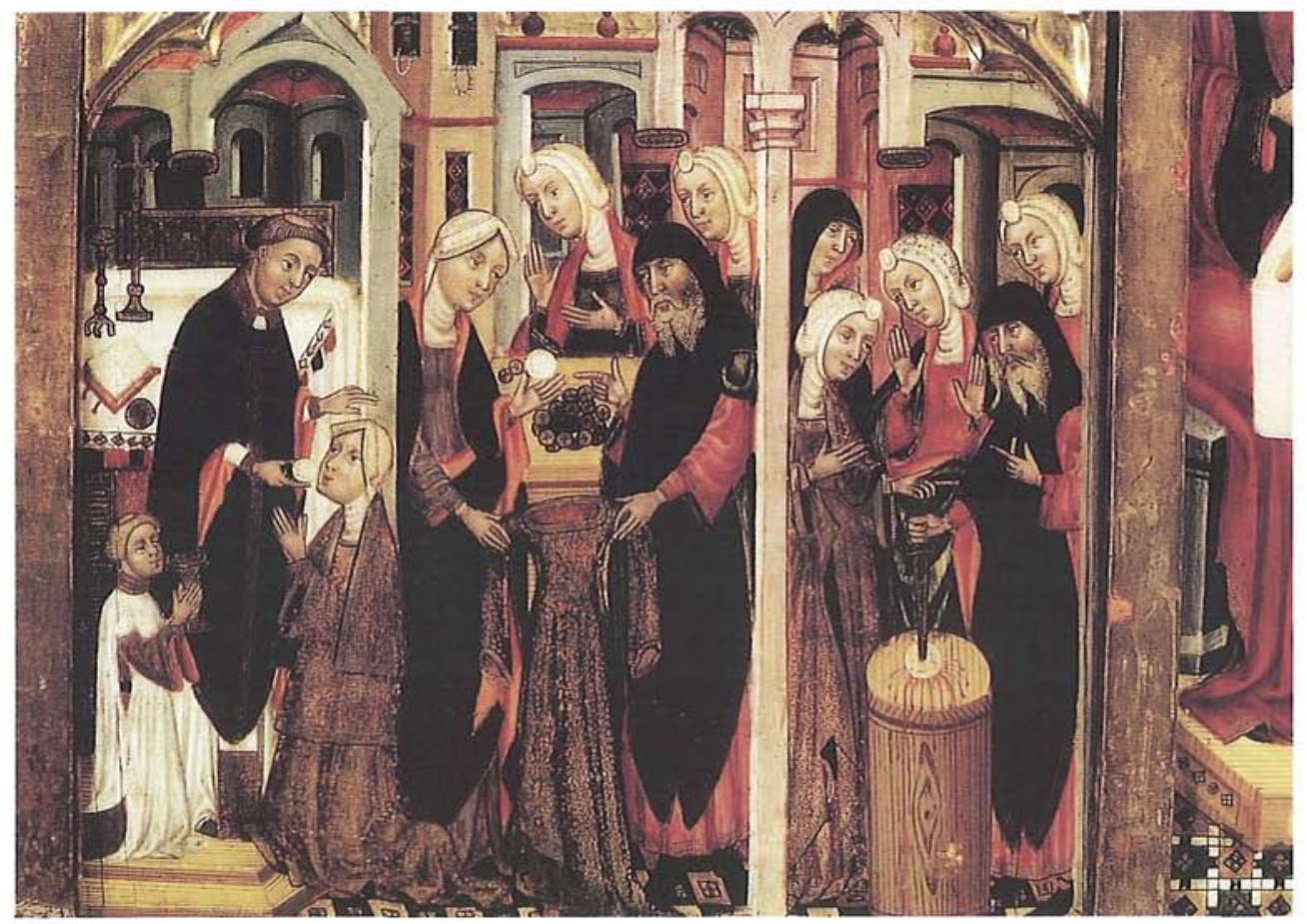

Fig. 1

Retablo de Villahermosa del Río (Castellón). Milagro de los Billettes. Comunión, cambio de la hostia por el vestido empeñado al judío y primer ultraje. 


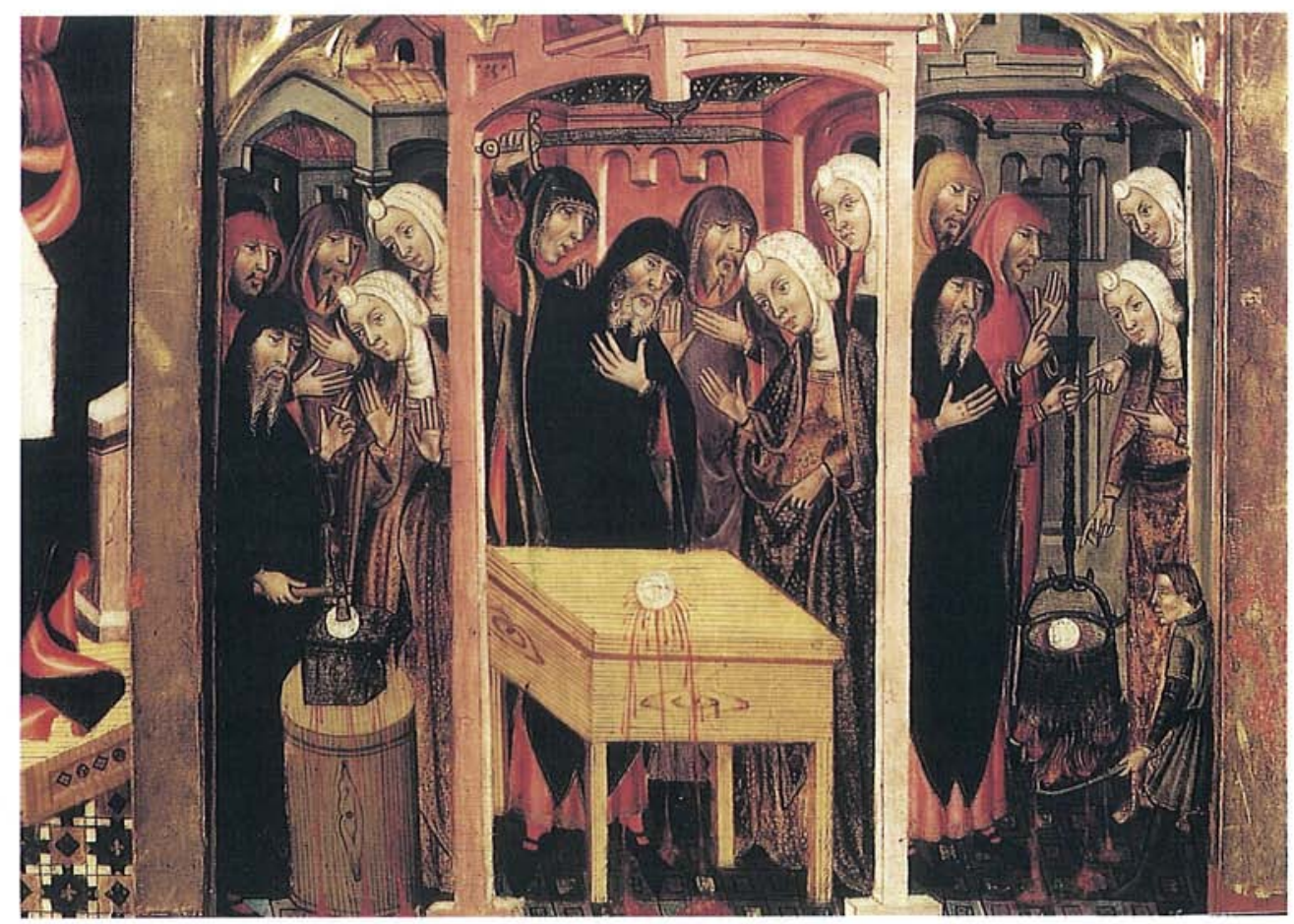

Fig. 2

Retablo de Villahermoso: otras secuencias consagradas a la profanación de la hostia. 


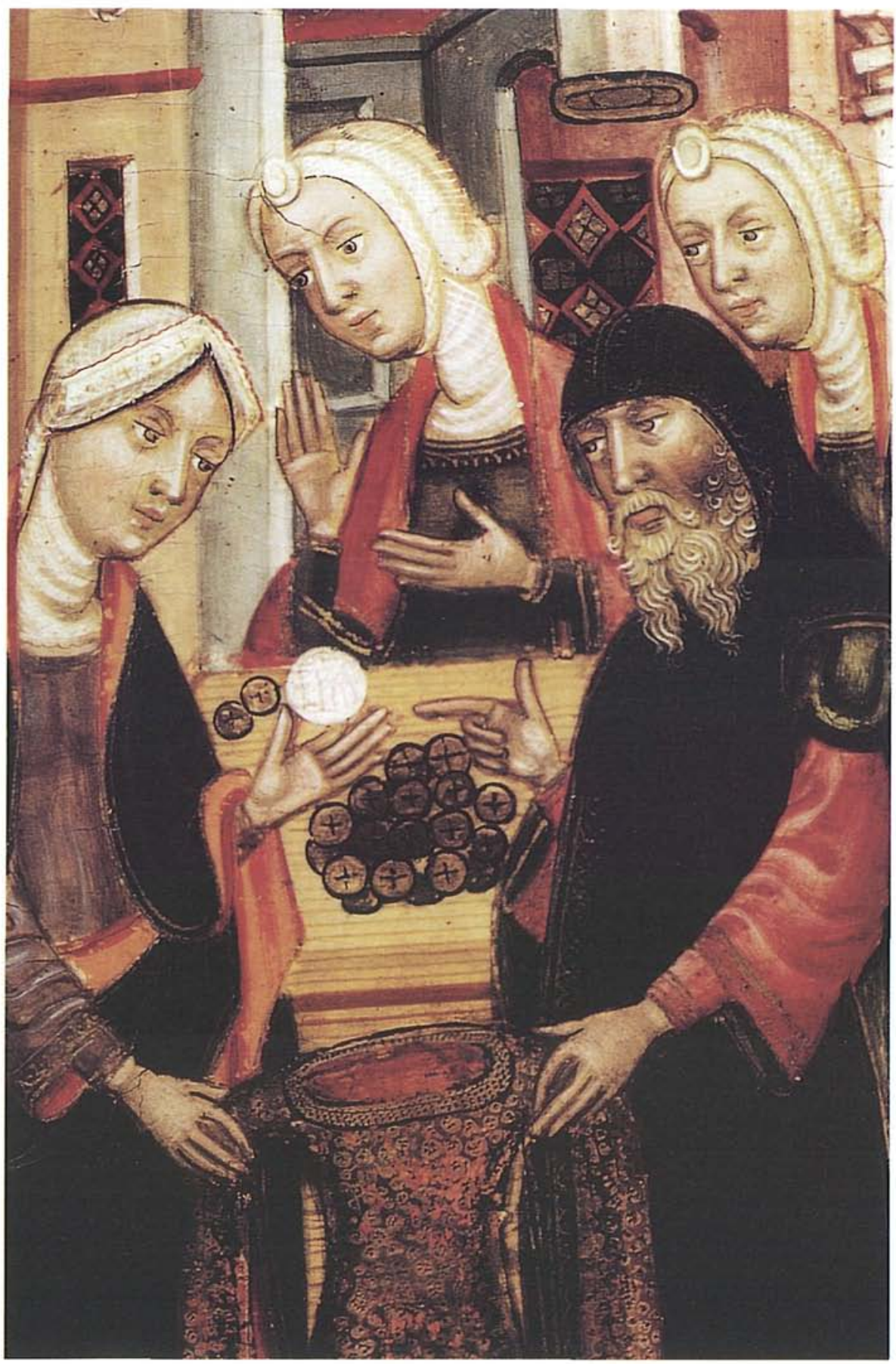

Fig. 3

Detalle del intercambio del vestido por la hostia en casa del judío prestamista. 